\title{
Different therapeutic associations of renin-angio- tensin system inhibitors with coronavirus disease 2019 compared with usual pneumonia
}

Hae-Young Lee ${ }^{1,2,3}$, Juhee Ahn ${ }^{4}$, Juhong Park ${ }^{4}$, Chang Kyung Kang ${ }^{3}$, Sung-Ho Won ${ }^{4,5}$, Dong Wook Kim ${ }^{6}$, Jong-Heon Park ${ }^{6,7}$, Ki-Hyun Chung ${ }^{8,9}$, Joon-Sung Joh ${ }^{8}$, JI Hwan Bang,10, Cheong Hee Kang ${ }^{6}$, Myoung-don $\mathrm{Oh}^{2,3,9}$, Wook Bum Pyun ${ }^{1,11}$, The Korean Society of Hypertension, and The National Committee for Clinical Management of Emerging Infectious Diseases

${ }^{1}$ Korean Society of Hypertension; ${ }^{2}$ Department of Internal Medicine, Seoul National University College of Medicine, Seoul; ${ }^{3}$ Department of Internal Medicine, Seoul National University Hospital, Seoul; ${ }^{4}$ Department of Public Health Sciences, ${ }^{5}$ nstitute of Health and Environment, Seoul National University, Seoul; ${ }^{6}$ National Health Insurance Service, Wonju; ${ }^{7}$ Department of Benefits Strategy, National Health Insurance Service, Wonju; ${ }^{8}$ National Medical Center, Seoul; ${ }^{9}$ National Committee for Clinical Management of Emerging Infectious Diseases, Seoul; ${ }^{10}$ The Central Infectious Disease Hospital, Seoul; ${ }^{11}$ Division of Cardiology, Department of Internal Medicine, Ewha Womans University School of Medicine, Seoul, Korea

Received: December 9, 2020 Revised : February 2, 2021 Accepted: February 3, 2021

\section{Correspondence to}

Wook Bum Pyun, M.D.

Korean Society of Hypertension and Division of Cardiology, Department of Internal Medicine, Ewha Womans University School of Medicine, 1071 Anyangcheonro, Yangcheon-gu, Seoul 07985, Korea

TEL: +82-2-6986-1627

FAX: +82-2-2650-6166

E-mail: pwb423@ewha.ac.kr https://orcid.org/0000-0002$6377-0411$
Background/Aims: Although it is near concluded that renin-angiotensin system inhibitors do not have a harmful effect on coronavirus disease 2019 (COVID-19), there is no report about whether angiotensin receptor blockers (ARBs) and angiotensin-converting enzyme inhibitors (ACEIs) offer any protective role. This study aimed to compare the association of ARBs and ACEIs with COVID-19-related mortality.

Methods: All patients with COVID-19 in Korea between January 19 and April 16, 2020 were enrolled. The association of ARBs and ACEIs with mortality within 60 days were evaluated. A comparison of hazard ratio (HR) was performed between COVID-19 patients and a retrospective cohort of pneumonia patients hospitalized in 2019 in Korea.

Results: Among 10,448 COVID-19 patients, ARBs and ACEIs were prescribed in $1,231(11.7 \%)$ and 57 (0.6\%) patients, respectively. After adjusting for age, sex, and history of comorbidities, the ARB group showed neutral association (HR, 1.034; $95 \%$ CI, 0.765 to $1.399 ; p=0.8270$ ) and the ACEI groups showed no significant associations likely owing to the small population size (HR, 0.736; 95\% CI, 0.314 to 1.726; $p=0.4810$ ). When comparing HR between COVID-19 patients and a retrospective cohort of patients hospitalized with pneumonia in 2019, the trend of ACEIs showed similar benefits, whereas the protective effect of ARBs observed in the retrospective cohort was absent in COVID-19 patients. Meta-analyses showed significant positive correlation with survival of ACEIs, whereas a neutral association between ARBs and mortality.

Conclusions: Although ARBs or ACEIs were not associated with fatal outcomes, potential beneficial effects of ARBs observed in pneumonia were attenuated in COVID-19.

Keywords: COVID-19; Pneumonia; Mortality; Angiotensin receptor antagonists; Angiotensin-converting enzyme inhibitors 


\section{INTRODUCTION}

When coronavirus disease 2019 (COVID-19, severe acute respiratory syndrome coronavirus 2 [SARS-CoV-2]) emerged as a global health problem, initial epidemiologic studies reported high prevalence of hypertension, diabetes mellitus and coronary artery disease $[1,2]$. These chronic diseases are highly prevalent among COVID-19 patients in Korea [3]. Given that SARS-CoV-2 enters target cells via angiotensin-converting enzyme 2 (ACE2) cell surface receptors [4], the use of angiotensin receptor blockers (ARBs) and angiotensin-converting enzyme inhibitors (ACEIs), which reportedly augment ACE2 levels [5], raise concern regarding antihypertensive agents, especially renin-angiotensin-aldosterone system (RAAS) inhibitors [6]. Although it is near concluded that ACEIs and ARBs do not increase mortality of COVID-19 patients [7-9], there are no reports as to whether ARBs or ACEIs have any protective role, which have been repetitively reported in pneumonia-related outcomes [10-12]. Given that beneficial effects have been reproducibly reported in pneumonia patients, neutral results suggest that there might be possible offset effects.

In the present study, we compared the association between the use of ARBs or ACEIs and COVID-19-related mortality in Korea. The hazard ratio (HR) was compared between COVID-19 patients and a retrospective cohort of patients hospitalized with pneumonia between January and June 2019 in Korea. Lastly, a meta-analysis was performed to compare the results of this study to those of other reports.

\section{METHODS}

\section{Study design}

This was a population-based cohort study supported by the Korea Disease Control and Prevention Agency (KDCA), the National Health Insurance Service (NHIS), and the Korean Society of Hypertension, and was approved by the Institutional Review Board of Seoul National University Hospital (No. 2003-102-1109). Informed consent was waived because the study was based on routinely collected administrative and claims data. All authors reviewed the manuscript for accuracy and completeness of the data.

\section{Data collection}

Data related to all 10,448 patients, who were infected with laboratory-confirmed SARS-CoV-2 until April 16, 2020 , in Korea [13,14], were retrieved from compiled information available from the NHIS. Information related to medical utilization was extracted from the National Health Information Database (NHID), a public database formed by the NHIS [15].

For indirect comparative analyses, the association between the use of ARBs and/or ACEIs and the mortality of pneumonia in hospitalized Korean patients between January and June 2019 was investigated using the information retrieved from the NHID [15].

\section{Study outcomes and definitions}

The association of ARBs and ACEIs with COVID-19-related mortality within 60 days was investigated. Disease-related mortality was defined as mortality during hospitalization with the indicated disease (COVID-19 or pneumonia) as the main disease code of hospitalization. All commercially available ARBs and ACEIs in Korea were included in the analysis. Medications were classified under ARBs (candesartan, irbesartan, valsartan, losartan, telmisartan, eprosartan, fimasartan, azilsartan, and olmesartan) and ACEIs (captopril, enalapril, lisinopril, perindopril, ramipril, and zofenopril). Dichotomous variables were created to identify the use of ARBs and ACEIs defined as a filled prescription for the medication of interest with sufficient supply to overlap the date of admission, assuming $80 \%$ compliance [16].

\section{Statistical analysis}

The association of clinical characteristics with mortality within 60 days was tested using bivariate statistics. Categorical variables were analyzed with a chi-square test. Continuous variables were analyzed using an analysis of variance test. Time to occurrence of the COVID-19-related death in patients prescribed with ARBs or ACEIs was analyzed using Kaplan-Meier graphs displaying failure functions. Statistical significance was assessed using a log-rank test. Cox proportional hazard models calculated estimates of unadjusted HRs and 95\% confidence intervals (CIs) for ARBs or ACEIs. The additional factors included in the models as covariates were age group, sex, and comorbidities including hypertension, type 2 diabetes mellitus, coronary heart diseases, heart failure, 

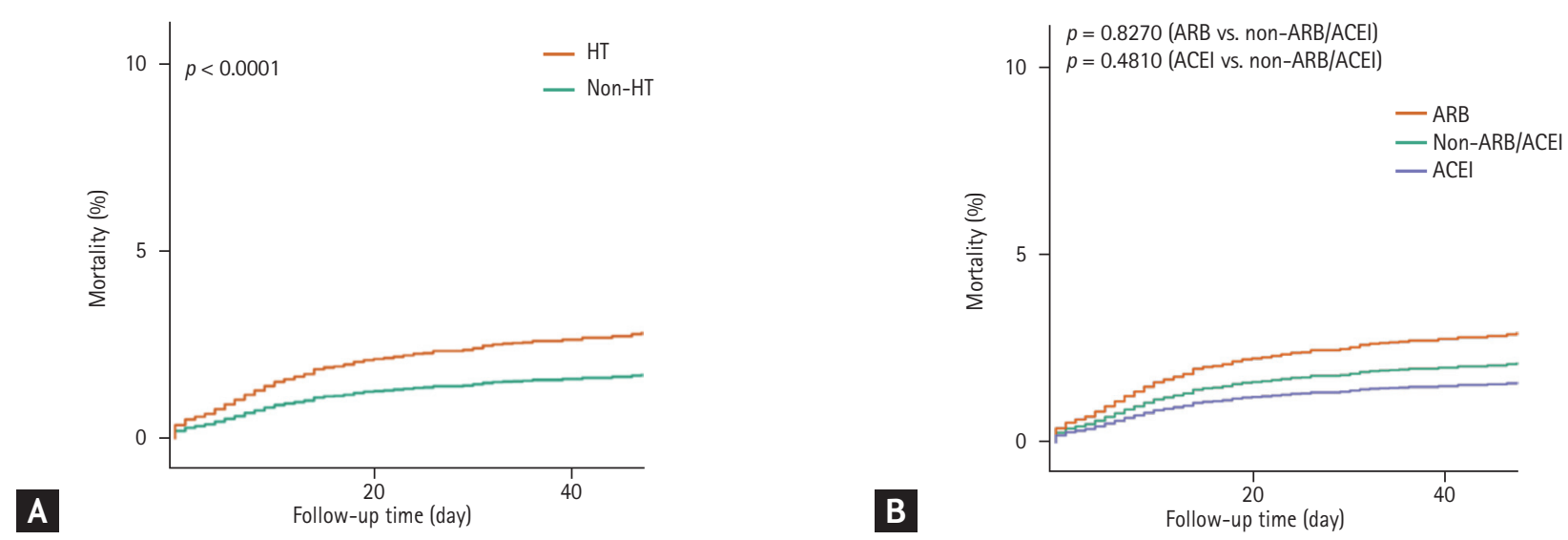

Figure 1. Survival within 60 days with prior statins or angiotensin receptor blockers (ARBs)/angiotensin-converting enzyme inhibitors (ACEIs) received. (A) Comparison with hypertension (HT) vs. non-HT (adjusted for age, sex, and history of comorbidities before the laboratory-confirmed diagnosis of coronavirus disease 2019). (B) Comparison with the patients treated with ARBs vs. ACEIs vs. the patients with non-ARBs/ACEIs (adjusted).

stroke, chronic obstructive pulmonary disorder (COPD), cancer, and chronic kidney diseases. We diagnosed the proportional hazard assumption using the Schoenfeld residuals plot. Comparisons were considered statistically significant if two-tailed $p$ values were less than 0.05 . All analyses were performed using SAS version 7.15 (SAS Institute Inc., Cary, NC, USA) and R version 4.0.0 (The R Development Core Team, Vienna, Austria).

\section{Meta-analysis}

Using PubMed searches of the MEDLINE database, we identified original papers published from 2019 to September 2020 in order to evaluate the association of ARBs or ACEIs with COVID-19 related death. The search strategy was based on the search terms "ARBs" or "ARB" or "angiotensin receptor blockers," or "ACEIs" or "ACEI" or "angiotensin converting enzyme inhibitors" or "angiotensin-converting enzyme inhibitors," and COVID-19 or COVID19 or coronavirus, and death or mortality. All available English abstracts were reviewed, and the full text was consulted as necessary to clarify eligibility status. We excluded the review articles, editorials and original papers that did not evaluate mortality (infection or hospitalization). Also, we performed an online search under the following terms: "COVID-19 and hypertension and ARBs or ACEIs." The initial search identified 259 articles. Of these, 25 articles were included for meta-analysis [17-33]. Details of the search strategy are summarized in Supplementary Fig. 1. The authors
(H.Y.L. and J.A.) reviewed all abstracts independently to evaluate the eligibility criteria and appropriateness of the research topics. If the inclusion criteria were met, the article was retrieved and reviewed thoroughly. There were no discrepancies in this process.

Statistical calculations and graphs were made using Rex software version 3.3.1 (RexSoft Inc., Seoul, Korea) [34]. Two-tailed statistical significance was set at the 5\% level, except for the Cochran's chi-square test for heterogeneity, which used a 10\% level of significance. The pooled results for each outcome are presented as odds ratios (OR) with 95\% CIs. Before applying approximate chi-square tests for heterogeneity, we clinically assessed studies for heterogeneity. Statistical heterogeneity was also examined with the $I^{2}$ statistics, where $I^{2}$ values $\geq$ $50 \%$ were considered to be indicators of a substantial level of heterogeneity. Forest plots were used for visual inspection. Funnel plots of effect estimates against its standard error and Copas selection model analysis were conducted to assess publication bias. We combined $p$ values for each OR and HR from meta-analysis using Fisher and Liptak's methods [35].

\section{RESULTS}

The present study includes data related to a total of 10,448 COVID-19 patients who were hospitalized or isolated in Korea from January 19, 2020, through April 16, 
Table 1. Clinical characteristics of coronavirus disease 2019 patients

\begin{tabular}{|c|c|c|c|c|c|}
\hline Characteristic & $\begin{array}{c}\text { Total } \\
(\mathrm{n}=10,448)\end{array}$ & $\begin{array}{c}\text { Non-ARB/ACEI } \\
(\mathrm{n}=9,170)\end{array}$ & $\begin{array}{c}\text { ARB } \\
(n=1,221)\end{array}$ & $\begin{array}{c}\text { ACEI } \\
(\mathrm{n}=57)\end{array}$ & $p$ value \\
\hline Age, yr & $44.87 \pm 19.81$ & $41.97 \pm 18.83$ & $65.50 \pm 13.01$ & $70.03 \pm 12.30$ & $<0.0001$ \\
\hline $0-19$ & $503(4.81)$ & $503(5.49)$ & o & o & $<0.0001$ \\
\hline $20-59$ & $7,293(69.80)$ & $6,879(75.02)$ & $403(33.01)$ & $11(19 \cdot 30)$ & \\
\hline $60-79$ & $2,124(20.33)$ & $1,476(16.10)$ & $616(50.45)$ & $32(56.14)$ & \\
\hline$\geq 80$ & $528(5.05)$ & $312(3.40)$ & $202(16.54)$ & $14(24 \cdot 56)$ & \\
\hline Female sex & $6,264(59 \cdot 95)$ & $5,547(60.49)$ & $697(57.08)$ & $20(35.09)$ & $<0.0001$ \\
\hline \multicolumn{6}{|l|}{ Comorbidity } \\
\hline Any $\geq$ comorbidity & $3,979(38.08)$ & $2,720(29.66)$ & $1,202(98.44)$ & $57(100.0)$ & $<0.0001$ \\
\hline Hypertension & $2,149(20.57)$ & $899(9.80)$ & $1,195(97.87)$ & $55(96.49)$ & $<0.0001$ \\
\hline Diabetes mellitus & $1,874(17.94)$ & $1,219(13.29)$ & $613(50.20)$ & $42(73.68)$ & $<0.0001$ \\
\hline Coronary artery disease & $633(6.06)$ & $358(3.90)$ & $240(19.66)$ & $35(61.40)$ & $<0.0001$ \\
\hline Heart failure & $345(3.30)$ & $188(2.05)$ & $133(10.89)$ & $24(42.11)$ & $<0.0001$ \\
\hline Stroke & $393(3.76)$ & $209(2.28)$ & $169(13.84)$ & $15(26.32)$ & $<0.0001$ \\
\hline COPD & $1,487(14.23)$ & $1,161(12.66)$ & $306(25.06)$ & $20(35.09)$ & $<0.0001$ \\
\hline Cancer (any) & $470(4.50)$ & $348(3 \cdot 79)$ & $110(9.01)$ & $12(21.05)$ & $<0.0001$ \\
\hline Chronic kidney disease & $112(1.07)$ & $50(0.55)$ & $59(4.83)$ & $3(5.26)$ & $<0.0001$ \\
\hline \multicolumn{6}{|l|}{ Medications } \\
\hline ARBs & $1,221(11.69)$ & - & $1,221(100)$ & - & - \\
\hline ACEIs & $57(0.55)$ & - & - & $57(100)$ & $<0.0001$ \\
\hline Death within 60 days & $228(2.18)$ & $127(1.38)$ & $95(7.78)$ & $6(10.53)$ & $<0.0001$ \\
\hline
\end{tabular}

Values are presented as mean \pm standard deviation or number $(\%)$.

ARB, angiotensin receptor blocker; ACEI, angiotensin-converting enzyme inhibitor; COPD, chronic obstructive pulmonary disorder.

2020. As of April 24, 2020, 228 of these patients (2.18\%) succumbed to death.

The demographic and clinical characteristics of patients are summarized in Table 1 . Of the patients evaluated, 38.1\% had at least one preexisting comorbid condition including hypertension (20.6\%) and diabetes mellitus (17.9\%). Patients prescribed with ARBs or ACEIs were more than 20 years older with a higher number of comorbidities than non-users and accounted for $11.7 \%$ and $0.6 \%$ of the overall cases, respectively. A small portion of the ACEI group corresponded to the prescription pattern reported in the Korean hypertension fact sheet [36]. Between the patients prescribed ARBs or ACEIs, the ACEI group showed a higher proportion of males (64.9\% vs. $40 \%$ in overall COVID-19 patients) and more comorbidities, including diabetes mellitus and cardiovascular disease. The mean age of hypertensive patients $(65.7 \pm 13.0$ years $)$ was more than 20 years greater than that of the non-hypertensive patients $(42.0 \pm 18.8$ years, $p<0.0001$ ).

The crude HR of old age ( $>65$ years) and hypertension were 36.5 (95\% CI, 24.6 to 54.2; $p<0.0001$ ) and 14.1 (95\% CI, 10.3 to 19.2; $p<0.0001$ ), respectively (Table 2). In multivariable regression analysis, old age ( $>65$ years) was by far the most important predictor of COVID-19-related mortality (Table 3). After adjusting for age, sex, and history of comorbidities, the association of chronic comorbid conditions including hypertension and diabetes mellitus remained significant (Fig. 1A).

In Cox regression analysis, the ARB group showed neutral association (HR, 1.034; 95\% CI, 0.765 to 1.399 ; $p=$ 0.8270 ) and the ACEI group showed no significant associations likely owing to the small population size (HR, 0.736; 95\% CI, 0.314 to 1.726; $p=0.4810$ ) (Fig. 1B). As there is a possibility that specific ARBs have a superior impact beyond class effect [5], we evaluated the subgroup anal- 
Table 2. Results of univariable regression analysis for mortality within 60 days

\begin{tabular}{|c|c|c|c|c|c|}
\hline Variable & No. patients & No. death & HR & $95 \%$ CI & $p$ value \\
\hline \multicolumn{6}{|l|}{ Age, yr } \\
\hline $0-64$ & 8,636 & 28 & 1 & & \\
\hline$\geq 65$ & 1,812 & 200 & 36.524 & $24.590-54.249$ & $<0.0001$ \\
\hline \multicolumn{6}{|l|}{ Sex } \\
\hline Male & 4,184 & 121 & 1 & & \\
\hline Female & 6,264 & 107 & 0.578 & $0.446-0.750$ & $<0.0001$ \\
\hline \multicolumn{6}{|c|}{ Comorbidity (upper, no; lower, yes) } \\
\hline \multirow[t]{2}{*}{ Hypertension } & 8,299 & 51 & 1 & & \\
\hline & 2,149 & 177 & 14.093 & $10.321-19.245$ & $<0.0001$ \\
\hline \multirow[t]{2}{*}{ Diabetes mellitus } & 8,574 & 95 & 1 & & \\
\hline & 1,874 & 133 & 6.628 & $5.093-8.625$ & $<0.0001$ \\
\hline \multirow[t]{2}{*}{ Coronary artery disease } & 9,815 & 173 & 1 & & \\
\hline & 633 & 55 & 5.129 & $3.787-6.948$ & $<0.0001$ \\
\hline \multirow[t]{2}{*}{ Stroke } & 10,055 & 182 & 1 & & \\
\hline & 393 & 46 & 7.020 & $5.078-9.703$ & $<0.0001$ \\
\hline \multirow[t]{2}{*}{ COPD } & 8,961 & 136 & 1 & & \\
\hline & 1,487 & 92 & 4.142 & $3.179-5.397$ & $<0.0001$ \\
\hline \multirow[t]{2}{*}{ Cancer (any) } & 9,978 & 196 & 1 & & \\
\hline & 470 & 32 & $3 \cdot 581$ & $2.465-5.204$ & $<0.0001$ \\
\hline \multirow[t]{2}{*}{ Chronic kidney disease } & 10,336 & 210 & 1 & & \\
\hline & 112 & 18 & 8.447 & $5.220-13.671$ & $<0.0001$ \\
\hline \multirow[t]{2}{*}{ Heart failure } & 10,103 & 175 & 1 & & \\
\hline & 345 & 53 & $19 \cdot 772$ & $7.186-13.290$ & $<0.0001$ \\
\hline \multicolumn{6}{|l|}{ Medication } \\
\hline Non-ACEIs/ARBs & 9,170 & 127 & 1 & & \\
\hline ARBs & 1,221 & 95 & 5.809 & $4.453-7.579$ & $<0.0001$ \\
\hline ACEIs & 57 & 6 & 8.174 & $3.606-18.529$ & $<0.0001$ \\
\hline Non-ACEIs/ARBs & 9,170 & 127 & 1 & & \\
\hline ARBs or ACEIs & 1,278 & 101 & 5.911 & $4.551-7.676$ & $<0.0001$ \\
\hline
\end{tabular}

HR, hazard ratio; CI, confidence interval; COPD, chronic obstructive pulmonary disorder. ACEI, angiotensin-converting enzyme inhibitor; ARB, angiotensin receptor blocker.

ysis according to individual drugs. Expectedly, no statistical significance was observed likely due to the small cohort sizes for each drug. No prevailing therapeutic effect was observed among the tested drugs (Supplementary Fig. 2).

The HR was compared between COVID-19 patients and a retrospective cohort of patients hospitalized with pneumonia between January and June 2019. Details related to comorbid conditions and administered medication were similarly extracted (Supplementary Table
1). Because there was no viral pneumonia epidemic in Korea, like SARS or Middle East respiratory syndrome (MERS), the 2019 pneumonia cohort was composed of bacterial and viral pneumonia patients combined. This retrospective cohort included 179,265 patients with a mean age of 39 years, of which $49.4 \%$ were females. The most common comorbid condition in the cohort was hypertension (33.3\%) followed by COPD (25.1\%) and diabetes mellitus $(23.4 \%)$. The mortality rate at 60 days was $7.4 \%$ and sharply increased among elderly patients $(\geq 60$ 
Table 3. Results of multivariable regression analysis of ARBs and ACEIs for the mortality within 60 days

\begin{tabular}{|c|c|c|c|c|c|}
\hline Variable & No. patients & No. death & HR & $95 \%$ CI & $p$ value \\
\hline \multicolumn{6}{|l|}{ Age, yr } \\
\hline $0-64$ & 8,636 & 28 & 1 & & \\
\hline$\geq 65$ & 1,812 & 200 & 16.400 & $10.487-25.646$ & $<0.0001$ \\
\hline \multicolumn{6}{|l|}{ Sex } \\
\hline Male & 4,184 & 121 & 1 & & \\
\hline Female & 6,264 & 107 & 0.556 & $0.427-0.723$ & $<0.0001$ \\
\hline \multicolumn{6}{|c|}{ Comorbidity (upper, no; lower, yes) } \\
\hline \multirow[t]{2}{*}{ Hypertension } & 8,299 & 51 & 1 & & \\
\hline & 2,149 & 177 & 2.423 & $1.621-3.623$ & $<0.0001$ \\
\hline \multirow[t]{2}{*}{ Diabetes mellitus } & 8,574 & 95 & 1 & & \\
\hline & 1,874 & 133 & 1.495 & $1.118-2.000$ & 0.0128 \\
\hline \multirow[t]{2}{*}{ Coronary artery disease } & 9,815 & 173 & 1 & & \\
\hline & 633 & 55 & 0.860 & $0.613-1.206$ & 0.3815 \\
\hline \multirow[t]{2}{*}{ Stroke } & 10,055 & 182 & 1 & & \\
\hline & 393 & 46 & 1.242 & $0.887-1.739$ & 0.2080 \\
\hline \multirow[t]{2}{*}{ COPD } & 8,961 & 136 & 1 & & \\
\hline & 1,487 & 92 & 1.509 & $1.141-1.996$ & 0.0040 \\
\hline \multirow[t]{2}{*}{ Cancer (any) } & 9,978 & 196 & 1 & & \\
\hline & 470 & 32 & 1.096 & $0.743-1.617$ & 0.6438 \\
\hline \multirow[t]{2}{*}{ Chronic kidney disease } & 10,336 & 210 & 1 & & \\
\hline & 112 & 18 & 1.709 & $1.038-2.814$ & 0.0352 \\
\hline \multirow[t]{2}{*}{ Heart failure } & 10,103 & 175 & 1 & & \\
\hline & 345 & 53 & 1.826 & $1.294-2.577$ & 0.0006 \\
\hline \multicolumn{6}{|l|}{ Medication } \\
\hline Non-ACEIs/ARBs & 9,170 & 127 & 1 & & \\
\hline ARBs & 1,221 & 95 & 1.034 & $0.765-1.399$ & 0.8270 \\
\hline ACEIs & 57 & 6 & 0.736 & $0.314-1.726$ & 0.4810 \\
\hline Non-ACEIs/ARBs & 9,170 & 127 & 1 & & \\
\hline ARBs or ACEIs & 1,278 & 101 & 1.011 & $0.750-1.361$ & 0.9446 \\
\hline
\end{tabular}

Adjusted for age, sex, history of medication (statins in case of ARBs/ACEIs), and history of comorbidities (hypertension, diabetes mellitus, cancer, COPD, stroke, coronary artery disease, heart failure, and chronic kidney disease) before the diagnosis of coronavirus disease 2019 .

ARB, angiotensin receptor blocker; ACEI, angiotensin-converting enzyme inhibitor; HR, hazard ratio; CI, confidence interval; COPD, chronic obstructive pulmonary disorder.

years) to a value higher than that seen with COVID-19 (Fig. 2A). Furthermore, the mortality was higher in patients with comorbidities, including hypertension (Supplementary Tables 2 and 3). Upon consideration of secondary factors, the results of the present study indicated a significantly lower risk of 60 days mortality with the use of ARBs (HR, 0.853 ; 95\% CI, 0.820 to $0.887 ; p<0.0001$ )
(Supplementary Table 3). Although ACEI groups showed an increase in $\mathrm{HR}$, there was no statistical significance (HR, 1.089; 95\% CI, 0.820 to 1.203; $p=0.0987$ ). When ARB and ACEI groups were merged, they showed a significant decrease in the mortality by about $14 \%$ (HR, o.866; 95\% CI, 0.834 to $0.900 ; p<0.0001)$. These results are in agreement with previously published data $[10-12,16,37]$. 


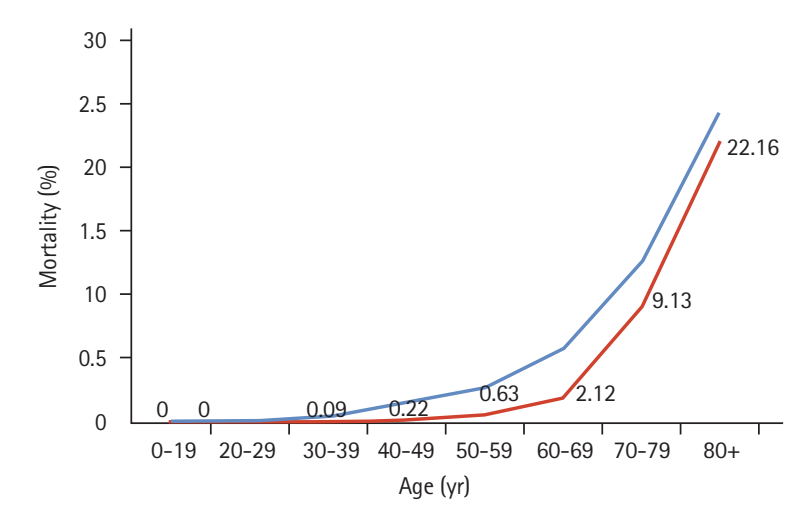

A — Pneumonia COVID-19

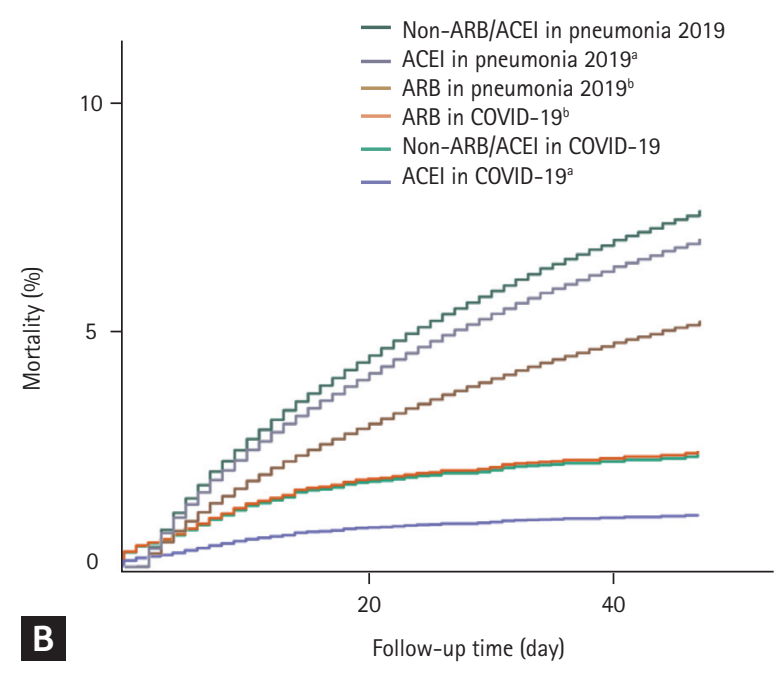

- Non-ARB/ACEI in pneumonia 2019

- ARB in COVID-19

- Non-ARB/ACEI in COVID-19

ACEI in COVID-19ª

Follow-up time (day)

Figure 2. Survival within 60 days in coronavirus disease 2019 (COVID-19) patients and retrospective cohort of patients hospitalized with pneumonia between January and June 2019. (A) Mortality rate according to age groups. (B) Comparison between patients treated with angiotensin receptor blockers (ARBs) or angiotensin-converting enzyme inhibitors (ACEIs) vs. patients with non-ARBs/ACEIs (adjusted). ${ }^{\mathrm{a}} \mathrm{p}=0.1319,{ }^{\mathrm{b}} \mathrm{p}=0.0040$ (pneumonia 2019 vs. COVID-19).

We compared HR between COVID-19 patients and a retrospective cohort of patients hospitalized with pneumonia 2019 in Korea. The trend of ACEIs was similar to that in COVID-19 patients ( $p=0.1319)$. However, the HRs of ARBs significantly differed between the retrospective cohort and the COVID-19 patients $(p=0.0040)$. The protective effect of ARBs observed in the retrospective cohort was lost in the COVID-19 patients (Table 3, Fig. 2B).

Lastly, we performed meta-analyses of ARB and ACEI groups using the data from previous studies. The $25 \mathrm{el}-$ igible studies and our study included 190,135 COVID-19 patients (Supplementary Fig. 1). Meta-analysis of ACEIs showed significant decrease in relative risk by $18 \%$ to $25 \%(p=0.028$ [Fisher], $p=0.017$ [Liptak]) (Fig. 3A). However, the ARB group showed neutral association (relative risk, 0.96 to $0.99 ; p=0.915$ [Fisher], $p=0.886$ [Liptak]) (Fig. $3 \mathrm{~B}$ ). Combined $p$ values for ORs and HRs are robust through Fisher and Liptak's methods. Interestingly, combined $p$ values in ARBs have the same trend with our results, whereas those for ACEIs show a significant protective effect for all-cause mortality (Table 4). We did not detect any significant publication bias by visual inspection of the funnel plots.

\section{DISCUSSION}

In the present study, we showed that ARBs and ACEIs are not associated with COVID-19-related fatal outcomes. While the ARB group showed a neutral association, the ACEI group showed no significant results, likely due to the small cohort size.

The RAAS is activated in sepsis, and angiotensin II, the main effector of the RAAS, has been recognized as an important inflammatory agent associated with organ failure and mortality [38]. Therefore, there is a competing hypothesis that ARBs and ACEIs may provide protection against pneumonia-related fatality. Enhanced expression of ACE and angiotensin II was reported in patients with acute respiratory distress syndrome and mechanical ventilation [39-41]. Injurious ventilation enhances the expression of the angiotensin type 1 receptor, a potent promoter of inflammatory response [40]. Angiotensin II, a pro-inflammatory mediator, induces damage to the pulmonary and vascular endothelial cells $[42,43]$. ARBs and ACEIs are reported to protect the vascular endothelium [44-46] and to possess immunomodulatory effects [47,48]. In vivo, angiotensin II deletion and generation of anti-inflammatory Ang 1-7 revealed the potential benefits of $\mathrm{ACE}_{2}$ in $\mathrm{H}_{7} \mathrm{~N}_{9}$ virus-induced acute lung injury [49].

In the initial reports of COVID-19, it was hypothesized that the use of ARBs or ACEIs may alter ACE2, which is a cell receptor of SARS-CoV-2, hence enhancing the infectivity of SARS-CoV-2. However, recent studies commonly reported that renin-angiotensin sys- 
ACEIs

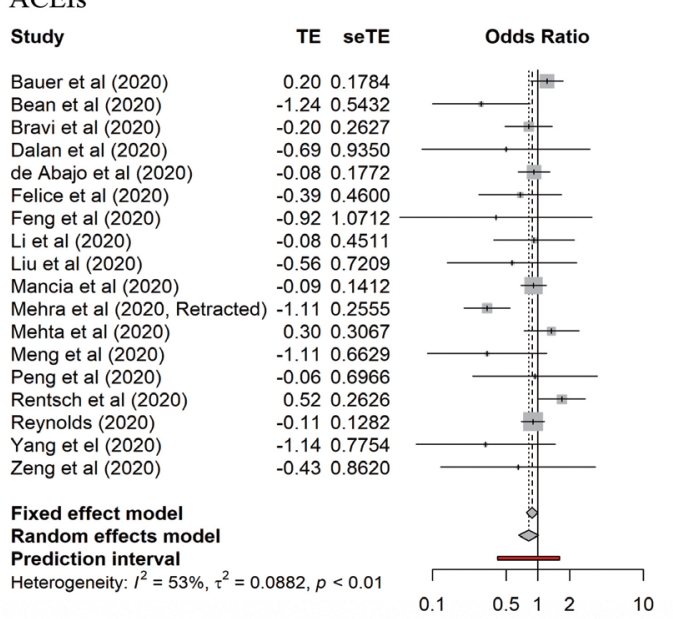

Study TE seTE Hazard Ratio

Fosbol et al (2020) $\quad-0.020 .1644$ Khera et al (2020) $\quad-0.030 .0920$ Mehra et al (2020, Retractred) $-0.57 \quad 0.0492$ Rossi et al (2020) $\quad-0.030 .1738$ Zhang et al (2020) Zhou et al (2020) Lee et al (2020) $\begin{array}{lll}-0.87 & 0.4047\end{array}$ $\begin{array}{lll}-0.71 & 0.4572 \\ -0.31 & 0.4346\end{array}$

Fixed effect model Random effects mode Prediction interval

Heterogeneity: $I^{2}=85 \%, \tau^{2}=0.1070, p<0.01$

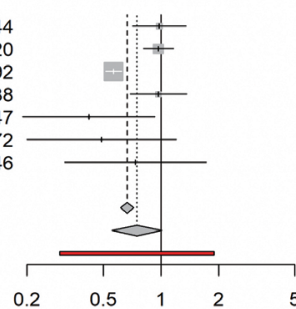

OR $\quad 95 \%-\mathrm{Cl} \begin{gathered}\text { Weight } \\ \text { (fixed) }\end{gathered} \begin{array}{r}\text { Weight } \\ \text { (random) }\end{array}$

$1.22[0.86 ; 1.73] \quad 12.4 \% \quad 10.5 \%$

$0.29[0.10 ; 0.84] \quad 1.3 \% \quad 3.3 \%$

$0.82[0.49 ; 1.37] \quad 5.7 \% \quad 8.0 \%$

$0.50[0.08 ; 3.12] \quad 0.5 \% \quad 1.3 \%$

$0.92[0.65 ; 1.30] \quad 12.6 \% \quad 10.5 \%$

$0.68[0.28 ; 1.68] \quad 1.9 \% \quad 4.2 \%$

$0.40[0.05 ; 3.27] \quad 0.3 \% \quad 1.0 \%$

$0.92[0.38 ; 2.23] \quad 1.9 \% \quad 4.3 \%$

$0.57[0.14 ; 2.35] \quad 0.8 \% \quad 2.1 \%$

$0.91[0.69 ; 1.20] \quad 19.8 \% \quad 11.6 \%$

$135[0.74 ; 2.46] \quad 42 \% \quad 8.2 \%$

$0.33[0.09 \cdot 1.21] \quad 0.9 \%-2.4 \%$

$0.94[0.24 ; 3.68] \quad 0.8 \%-2.4 \%$

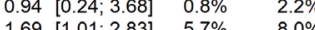

$1.69[1.01,2.83] \quad 5.7 \% \quad 8.0 \%$

$0.32[0.07-1.46]-0.7 \%-12.0 \%$

$\begin{array}{llll}0.32 & {[0.07 ; 1.46]} & 0.7 \% & 1.8 \% \\ 0.65 & {[0.12 ; 3.52]} & 0.5 \% & 1.5 \%\end{array}$

$0.89[0.78 ; 1.00] 100.0 \%$

$\begin{array}{rrr}0.89[0.78 ; 1.00] & 100.0 \% & -- \\ 0.82[0.66 ; 1.02] & -- & 100.0 \%\end{array}$ [0.42; 1.60$]$

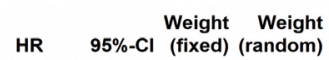

$\begin{array}{lll}0.98 & {[0.71 ; 1.35] \quad 6.0 \% \quad 17.4 \%}\end{array}$

$0.97[0.81 ; 1.16] \quad 19.1 \% \quad 20.2 \%$

$0.57[0.51 ; 0.62] \quad 66.9 \% \quad 21.4 \%$

$0.97[0.69 ; 1.36] \quad 5.4 \% \quad 17.0 \%$

$0.42[0.19 ; 0.93] \quad 1.0 \% \quad 8.6 \%$

$0.49[0.20 ; 1.20] \quad 0.8 \% \quad 7.4 \%$

$0.74[0.31 ; 1.73] \quad 0.9 \% \quad 7.9 \%$

$0.67[0.62 ; 0.72] 100.0 \%$

$0.75[0.56 ; 1.01] \quad--100.0 \%$

Combining $p=0.028$ (Fisher), 0.017 (Liptak)

ARBs

\begin{tabular}{|c|c|c|}
\hline Study & TE & SETE \\
\hline Bauer et al (2020) & 0.00 & 0.3852 \\
\hline Bravi et al (2020) & -0.19 & 0.2586 \\
\hline Dalan et al (2020) & 1.05 & 0.9928 \\
\hline de Abajo et al (2020) & 0.22 & 0.1733 \\
\hline Feng et al (2020) & -0.73 & 0.5605 \\
\hline Li et al (2020) & -0.26 & 0.3215 \\
\hline Liu et al (2020) & -1.39 & 0.6952 \\
\hline Mancia et al (2020) & -0.19 & 0.1407 \\
\hline Mehra et al (2020, Retracted) & 0.21 & 0.1767 \\
\hline Mehta et al (2020) & 0.11 & 0.3270 \\
\hline Meng et al (2020) & -1.11 & 0.6629 \\
\hline Peng et al (2020) & -0.06 & 0.6966 \\
\hline Rentsch et al (2020) & 0.52 & 0.2626 \\
\hline Reynolds (2020) & -0.07 & 0.1306 \\
\hline Yang et al (2020) & -1.14 & 0.7754 \\
\hline Zeng et al (2020) & -0.43 & 0.8620 \\
\hline $\begin{array}{l}\text { Fixed effect model } \\
\text { Random effects model } \\
\text { Prediction interval } \\
\text { Heterogeneity: } I^{2}=33 \%, \tau^{2}=\end{array}$ & & \\
\hline
\end{tabular}

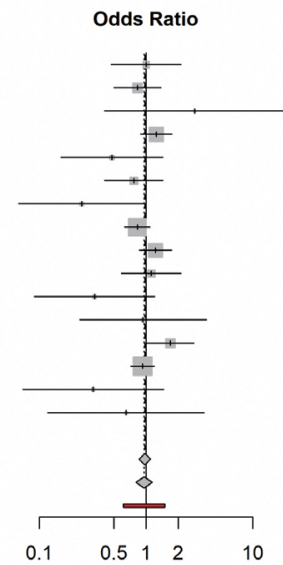

95\%-Cl Weight Weight $0.25[0.06 ; 0.98] \quad 0.9 \% \quad 1.6 \%$ Study $0.99[0.87 ; 1.14] \quad--\quad 100.0 \%$ B
$1.00[0.47 ; 2.13] \quad 2.8 \%-4.6 \%$ $0.83[0.50 ; 1.38] \quad 6.1 \% \quad 8.2 \%$ $2.87[0.41 ; 20.09] \quad 0.4 \% \quad 0.8 \%$ $1.25[0.89 ; 1.76] \quad 13.7 \% \quad 12.8 \%$

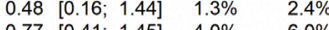
$0.77[0.41,1.45] \quad 4.0 \%-6.0 \%$ $0.83[0.63 ; 1.09] \quad 20.8 \% \quad 15.2 \%$ $1.23[0.87 ; 1.74] \quad 13.2 \% \quad 12.6 \%$ $1.12[0.59 ; 2.13] \quad 3.8 \% \quad 5.9 \%$ $0.33[0.09 ; 1.21] \quad 0.9 \% \quad 1.8 \%$ $0.94[0.24 ; 3.68] \quad 0.8 \% \quad 16 \%$ $1.69[1.01 ; 2.83] \quad 6.0 \% \quad 8.0 \%$ $03[0.72 ; 1.20] 24.1 \%-16.0 \%$ $.32[0.07 ; 1.46] \quad 0.7 \% \quad 1.3 \%$ $0.32[0.07 ; 1.46] \quad 0.7 \% \quad 1.3 \%$

$0.98[0.86 ; 1.11] 100.0 \%$ $0.96[0.80 ; 1.15] \quad--100.0 \%$ $[0.61 ; 1.50]$

Weight Weight Hazard Ratio HR 95\%-Cl (fight Weight $0.80[0.60 ; 1.07] \quad 5.4 \% \quad 14.5 \%$ $1.15[0.95 ; 1.39] \quad 12.4 \% \quad 22.4 \%$ $0.99[0.91 ; 1.07] \quad 72.5 \% \quad 34.8 \%$ $1.16[0.83 ; 1.62] \quad 4.0 \% \quad 11.8 \%$ $0.42[0.19 ; 0.93] \quad 0.7 \% \quad 2.8 \%$ $1.03[0.77 ; 1.40] \quad 5.0 \% \quad 13.6 \%$ $1.00[0.93 ; 1.07] 100.0 \%$

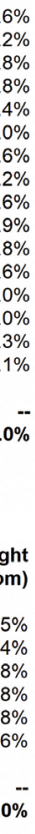

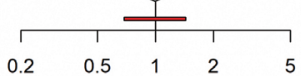

Figure 3. Meta-analysis of survival with prior use of angiotensin-converting enzyme inhibitors (ACEIs) and angiotensin receptor blockers (ARBs). Gray squares represent treatment-to-control ratios in the reports; their size is proportional to the number of events. The $95 \%$ confidence intervals (CIs) for individual reports are denoted by lines, while those for pooled odds ratios are denoted by diamonds. (A) ACEIs. (B) ARBs. TE, estimated treatment effect; seTE, standard error of pooled estimated treatment effect; OR, odds ratio; HR, hazard ratio. 
Table 4. Comparison of hazard ratio between COVID-19 patients and a retrospective cohort of patients hospitalized with pneumonia between January and June 2019 in Korea

\begin{tabular}{|c|c|c|c|}
\hline & $\mathrm{Df}$ & Wald chi-square & $p$ value \\
\hline \multicolumn{4}{|c|}{ Contrasts statement (COVID-19 or retrospective cohort) } \\
\hline $\mathrm{H}_{\mathrm{o}}: \beta_{\text {ARBs } \mid \text { COVID-19 }}=\beta_{\text {ARBs } \mid \text { pneumonia }}$ & 1 & 8.2740 & 0.0040 \\
\hline $\mathrm{H}_{\mathrm{o}}: \beta_{\mathrm{ACEI} \mid \text { COVID-19 }}=\beta_{\mathrm{ACEi}} \mid$ pneumonia & 1 & 2.2706 & 0.1319 \\
\hline
\end{tabular}

COVID-19, coronavirus disease 2019; ARB, angiotensin receptor blocker; ACEI, angiotensin-converting enzyme inhibitor.

tem inhibitors did not increase SARS-CoV-2 infectivity $[23,24]$. Another hypothesis is that ARBs are less effective in attenuating inflammatory response in COVID-19 than in typical pneumonia. Interestingly, ARBs showed a loss of beneficial effect on COVID-19 conflicting with previous meta-analysis results in pneumonia patients $[11,16]$, and with data from pneumonia patients in Korea in 2019. Although several studies, which urgently reported no harm with ARBs and ACEIs in COVID-19 patients (see references for the meta-analysis), given that beneficial effects have been reproducibly reported in pneumonia patients, neutral results suggest that there might be possible offset effects. Although ARBs showed non-inferior cardiovascular protective effect to ACEIs in a large scaled randomized controlled trial [50], several meta-analyses suggested superior cardiovascular protecting effects of ACEIs over ARBs in high risk hypertensive patients [51,52]. A replenished effect of bradykinin by ACEIs, which is reduced in cardiovascular disease status, might exert a superior anti-inflammatory effect over ARBs [53]. The lack of benefit of ARBs observed in this study might be significant, because multiple clinical trials using ARBs are recruiting patients based on the initial clinical attention associated with ACE2-COVID-19 issues (14 studies, with the search terms of "COVID-19" and "ARBs," identified in ClinicalTrials.gov, accessed January 25, 2021).

The current study has several limitations. Firstly, data related to drug exposure were measured based on claim data. Hence, detailed information about drug exposure, such as adherence to the medication or discontinuation during COVID-19 hospitalization, remains unknown. However, the Korean Society of Hypertension and the Korean Society of Cardiology formally recommended that doctors continue administering anti-hypertensive medication without change during COVID-19 treat- ment [54-56]. Therefore, we rationally assumed that the infected hypertensive patients continued the use of anti-hypertensive medications during the period of hospitalization. However, there might be a difference in the compliance of antihypertensive medications. Indeed, it was reported that about $26 \%$ of COVID-19 patients with hypertension might exhibited drug compliance below 80\% [8], which potentially influenced the association between the use of ARBs or ACEIs and mortality in COVID-19 patients either directly or indirectly through the healthy adherer effect or selective prescribing [57]. Secondly, although we evaluated a total of 10,448 COVID-19 patients who were hospitalized in Korea from January 19, 2020, through April 15, 2020, the interpretation of our findings is influenced by the limited sample size. Notably, the prescription rate of ACEIs was barely $3 \%$ in hypertensive patients likely because of dry cough, a common side effect among Asians [36]. To overcome this limitation, we compared the results with a retrospective cohort of more than 170,000 pneumonia patients hospitalized from January to June in 2019 to include more than 1,000 patients with prescribed use of ACEIs, assuming that $3 \%$ of prescription rate had $40 \%$ hypertension prevalence among all pneumonia cases. The results indicated similar trends to those followed by COVID-19 and pneumonia cases. Also, we performed meta-analyses of ARBs and ACEIs using the data from previous studies merged with our study, thus evaluating 145,124 patients. The results of the meta-analysis supported the findings of our study.

In conclusion, while ARBs or ACEIs were not associated with fatal outcomes, the possible beneficial effect of ARBs observed in pneumonia patients was not observed in COVID-19 patients. The findings of this paper implicate that ARBs might have no role as a COVID-19 therapeutic. 


\section{KEY MESSAGE}

1. In coronavirus disease 2019 (COVID-19) patients in Korea, angiotensin receptor blockers (ARBs) showed neutral association, whereas angiotensin converting enzyme (ACE) inhibitors showed no significant associations likely owing to the small population size.

2. When comparing a retrospective cohort of patients hospitalized with pneumonia in 2019 , ACE inhibitors showed similar benefits. In contrast, the protective effect of ARBs was not reproduced in the COVID-19 cohort.

3. Meta-analysis merging the data from our and previously published studies showed significant benefit of ACE inhibitors, but a neutral association between ARBs and the mortality.

\section{Conflict of interest}

No potential conflict of interest relevant to this article was reported.

\section{Acknowledgments}

This study was supported by a Research Grant from the Korea Disease Control and Prevention Agency (KDCA) (\#4838-330-320-01) and the Seoul National University Hospital (\#04-2020-0030).

\section{REFERENCES}

1. Wu Z, McGoogan JM. Characteristics of and important lessons from the coronavirus disease 2019 (COVID-19) outbreak in China: summary of a report of 72314 cases from the Chinese center for disease control and prevention. JAMA 2020;323:1239-1242.

2. Ahn MY, Oh DH, Kim S, et al. Four cases of coronavirus disease 2019 in the early stage of pandemic of South Korea: a single public hospital experience. Korean J Intern Med 2020;35:788-792.

3. Lee HW, Yoon SY, Lee JK, et al. Clinical implication and risk factor of pneumonia development in mild coronavirus disease 2019 patients. Korean J Intern Med 2021;36:1-10.

4. Chen Q, Liang M, Li Y, et al. Mental health care for medical staff in China during the COVID-19 outbreak. Lancet
Psychiatry 2020;7:e15-e16.

5. Ferrario CM, Jessup J, Chappell MC, et al. Effect of angiotensin-converting enzyme inhibition and angiotensin II receptor blockers on cardiac angiotensin-converting enzyme 2. Circulation 2005;111:2605-2610.

6. Kreutz R, Algharably EAE, Azizi M, et al. Hypertension, the renin-angiotensin system, and the risk of lower respiratory tract infections and lung injury: implications for COVID-19. Cardiovasc Res 2020;116:1688-1699.

7. Xu J, Teng Y, Shang L, et al. The effect of prior ACEI/ARB treatment on COVID-19 susceptibility and outcome: a systematic review and meta-analysis. Clin Infect Dis 2020 Oct 20 [Epub]. https://doi.org/10.1093/cid/ciaa1592.

8. Kim J, Kim DW, Kim KI, et al. Compliance of antihypertensive medication and risk of coronavirus disease 2019: a cohort study using big data from the Korean National Health Insurance Service. J Korean Med Sci 2020;35:e232.

9. Jung SY, Choi JC, You SH, Kim WY. Association of reninangiotensin-aldosterone system inhibitors with coronavirus disease 2019 (COVID-19)-related outcomes in Korea: a nationwide population-based cohort study. Clin Infect Dis 2020;71:2121-2128.

10. Mortensen EM, Nakashima B, Cornell J, et al. Populationbased study of statins, angiotensin II receptor blockers, and angiotensin-converting enzyme inhibitors on pneumoniarelated outcomes. Clin Infect Dis 2012;55:1466-1473.

11. Henry C, Zaizafoun M, Stock E, Ghamande S, Arroliga AC, White HD. Impact of angiotensin-converting enzyme inhibitors and statins on viral pneumonia. Proc (Bayl Univ Med Cent) 2018;31:419-423.

12. Myles PR, Hubbard RB, Gibson JE, Pogson Z, Smith CJ, McKeever TM. The impact of statins, ACE inhibitors and gastric acid suppressants on pneumonia mortality in a UK general practice population cohort. Pharmacoepidemiol Drug Saf 2009;18:697-703.

13. Park WB, Kwon NJ, Choi SJ, et al. Virus isolation from the first patient with SARS-CoV-2 in Korea. J Korean Med Sci 2020;35:e84.

14. Corman VM, Landt O, Kaiser M, et al. Detection of 2019 novel coronavirus (2019-nCoV) by real-time RT-PCR. Euro Surveill 2020;25:2000045.

15. Seong SC, Kim YY, Khang YH, et al. Data resource profile: the National Health Information Database of the National Health Insurance Service in South Korea. Int J Epidemiol 2017;46:799-800.

16. Wu A, Good C, Downs JR, et al. The association of cardio- 
protective medications with pneumonia-related outcomes. PLoS One 2014;9:e85797.

17. Mehra MR, Desai SS, Ruschitzka F, Patel AN. Hydroxychloroquine or chloroquine with or without a macrolide for treatment of COVID-19: a multinational registry analysis. Lancet 2020.

18. Mancia G, Rea F, Ludergnani M, Apolone G, Corrao G. Renin-angiotensin-aldosterone system blockers and the risk of COVID-19. N Engl J Med 2020;382:2431-2440.

19. Mehra MR, Desai SS, Kuy S, Henry TD, Patel AN. Cardiovascular disease, drug therapy, and mortality in COVID-19. N Engl J Med 2020;382:e102.

20. Zhang $\mathrm{P}$, Zhu L, Cai J, et al. Association of inpatient use of angiotensin-converting enzyme inhibitors and angiotensin II receptor blockers with mortality among patients with hypertension hospitalized with COVID-19. Circ Res 2020;126:1671-1681.

21. Li J, Wang X, Chen J, Zhang H, Deng A. Association of renin-angiotensin system inhibitors with severity or risk of death in patients with hypertension hospitalized for coronavirus disease 2019 (COVID-19) infection in Wuhan, China. JAMA Cardiol 2020;5:825-830.

22. Meng J, Xiao G, Zhang J, et al. Renin-angiotensin system inhibitors improve the clinical outcomes of COVID-19 patients with hypertension. Emerg Microbes Infect 2020;9:757-760.

23. de Abajo FJ, Rodriguez-Martin S, Lerma V, et al. Use of renin-angiotensin-aldosterone system inhibitors and risk of COVID-19 requiring admission to hospital: a casepopulation study. Lancet 2020;395:1705-1714.

24. Reynolds HR, Adhikari S, Pulgarin C, et al. Reninangiotensin-aldosterone system inhibitors and risk of covid-19. N Engl J Med 2020;382:2441-2448.

25. Khera R, Clark C, Lu Y, et al. Association of angiotensinconverting enzyme inhibitors and angiotensin receptor blockers with the risk of hospitalization and death in hypertensive patients with coronavirus disease-19. medRxiv 2020 May 19. https://doi.org/10.1101/2020.05.17.20104943.

26. Bean DM, Kraljevic Z, Searle T, et al. Angiotensinconverting enzyme inhibitors and angiotensin II receptor blockers are not associated with severe COVID-19 infection in a multi-site UK acute hospital trust. Eur J Heart Fail 2020;22:967-974.

27. Feng Y, Ling Y, Bai T, et al. COVID-19 with different severities: a multicenter study of clinical features. Am J Respir Crit Care Med 2020;201:1380-1388.
28. Rentsch CT, Kidwai-Khan F, Tate JP, et al. Patterns of COVID-19 testing and mortality by race and ethnicity among United States veterans: a nationwide cohort study. PLoS Med 2020;17:e1003379.

29. Peng YD, Meng K, Guan HQ, et al. Clinical characteristics and outcomes of 112 cardiovascular disease patients infected by 2019-nCoV. Zhonghua Xin Xue Guan Bing Za Zhi 2020;48:450-455.

30. Zeng Z, Sha T, Zhang Y, et al. Hypertension in patients hospitalized with COVID-19 in Wuhan, China: a singlecenter retrospective observational study. medRxiv $2020 \mathrm{Apr}$ 11. https://doi.org/10.1101/2020.04.06.20054825.

31. Yang G, Tan Z, Zhou L, et al. Angiotensin II receptor blockers and angiotensin-converting enzyme inhibitors usage is associated with improved inflammatory status and clinical outcomes in COVID-19 patients with hypertension. medRxiv 2020 Apr 4. https://doi.org/10.1101/2020.03.31.2003 8935 .

32. Giorgi Rossi P, Marino M, Formisano D, et al. Characteristics and outcomes of a cohort of COVID-19 patients in the Province of Reggio Emilia, Italy. PLoS One 2020;15:e0238281.

33. Yan F, Huang F, Xu J, et al. Antihypertensive drugs are associated with reduced fatal outcomes and improved clinical characteristics in elderly COVID-19 patients. Cell Discov 2020;6:77.

34. RexSoft. Rex: Excel-based statistical analysis software [Internet]. Seoul (KR): RexSoft, 2018 [cited 2020 Mar 11]. Available from: http://rexsoft.org/.

35. Won S, Morris N, Lu Q, Elston RC. Choosing an optimal method to combine P-values. Stat Med 2009;28:1537-1553.

36. Korean Society Hypertension (KSH); Hypertension Epidemiology Research Working Group, Kim HC, Cho MC. Korea hypertension fact sheet 2018. Clin Hypertens 2018;24:13.

37. Caldeira D, Alarcao J, Vaz-Carneiro A, Costa J. Risk of pneumonia associated with use of angiotensin converting enzyme inhibitors and angiotensin receptor blockers: systematic review and meta-analysis. BMJ 2012;345:e426o.

38. Hsu WT, Galm BP, Schrank G, et al. Effect of reninangiotensin-aldosterone system inhibitors on short-term mortality after sepsis: a population-based cohort study. Hypertension 2020;75:483-491.

39. Wenz M, Steinau R, Gerlach H, Lange M, Kaczmarczyk G. Inhaled nitric oxide does not change transpulmonary angiotensin II formation in patients with acute respiratory distress syndrome. Chest 1997;112:478-483. 
40. Jerng JS, Hsu YC, Wu HD, et al. Role of the reninangiotensin system in ventilator-induced lung injury: an in vivo study in a rat model. Thorax 2007;62:527-535.

41. Wosten-van Asperen RM, Lutter R, Haitsma JJ, et al. ACE mediates ventilator-induced lung injury in rats via angiotensin II but not bradykinin. Eur Respir J 2008;31:363371.

42. Wang R, Zagariya A, Ibarra-Sunga O, et al. Angiotensin II induces apoptosis in human and rat alveolar epithelial cells. Am J Physiol 1999;276:L885-L889.

43. Jung KH, Chu K, Lee ST, et al. Blockade of AT1 receptor reduces apoptosis, inflammation, and oxidative stress in normotensive rats with intracerebral hemorrhage. J Pharmacol Exp Ther 2007;322:1051-1058.

44. Wiel E, Pu Q, Leclerc J, et al. Effects of the angiotensinconverting enzyme inhibitor perindopril on endothelial injury and hemostasis in rabbit endotoxic shock. Intensive Care Med 2004;30:1652-1659.

45. Chen C, Zhang Z, Li Z, et al. Losartan attenuates microvascular permeability in mechanical ventilator-induced lung injury in diabetic mice. Mol Biol Rep 2014;41:809-814.

46. Asmussen S, Bartha E, Olah G, et al. The angiotensinconverting enzyme inhibitor captopril inhibits poly(adpribose) polymerase activation and exerts beneficial effects in an ovine model of burn and smoke injury. Shock 2011;36:402-409.

47. Gullestad L, Aukrust P, Ueland T, et al. Effect of high- versus low-dose angiotensin converting enzyme inhibition on cytokine levels in chronic heart failure. J Am Coll Cardiol 1999;34:2061-2067.

48. Shao J, Nangaku M, Miyata T, et al. Imbalance of T-cell subsets in angiotensin II-infused hypertensive rats with kidney injury. Hypertension 2003;42:31-38.

49. Yang $\mathrm{P}, \mathrm{Gu} \mathrm{H}, \mathrm{Zhao} \mathrm{Z}$, et al. Angiotensin-converting enzyme 2 ( $\left.\mathrm{ACE}_{2}\right)$ mediates influenza $\mathrm{H}_{7} \mathrm{~N}_{9}$ virus-induced acute lung injury. Sci Rep 2014;4:7027.

50. ONTARGET Investigators, Yusuf S, Teo KK, et al. Telmisartan, ramipril, or both in patients at high risk for vascular events. N Engl J Med 2008;358:1547-1559.

51. Lv X, Zhang Y, Niu Y, Song Q, Zhao Q. Comparison of angiotensin-converting enzyme inhibitors and angiotensin II receptor blockers on cardiovascular outcomes in hypertensive patients with type 2 diabetes mellitus: a PRISMA-compliant systematic review and meta-analysis. Medicine (Baltimore) 2018;97:00256.

52. Brugts JJ, van Vark L, Akkerhuis M, et al. Impact of reninangiotensin system inhibitors on mortality and major cardiovascular endpoints in hypertension: a numberneeded-to-treat analysis. Int J Cardiol 2015;181:425-429.

53. Ceconi C, Fox KM, Remme WJ, et al. ACE inhibition with perindopril and endothelial function. Results of a substudy of the EUROPA study: PERTINENT. Cardiovasc Res 2007;73:237-246.

54. Park S, Lee HY, Cho EJ, et al. Is the use of RAS inhibitors safe in the current era of COVID-19 pandemic? Clin Hypertens 2020;26:11.

55. Lee KY, Lee BK, Kim WJ, et al. Consensus statement on coronary intervention during the coronavirus disease 2019 (COVID-19) pandemic: from the Korean Society of Interventional Cardiology (KSIC). Korean Circ J 2020;50:974983.

56. Lee KY, Lee BK, Kim WJ, et al. Consensus statement on coronary intervention during the coronavirus disease 19 pandemic: from the Korean Society of Interventional Cardiology. Korean J Intern Med 2020;35:749-757.

57. Shrank WH, Patrick AR, Brookhart MA. Healthy user and related biases in observational studies of preventive interventions: a primer for physicians. J Gen Intern Med 2011;26:546-550. 
Supplementary Table 1. Clinical characteristics of pneumonia patients in Korea (2019)

\begin{tabular}{|c|c|c|c|c|c|}
\hline Characteristic & $\begin{array}{c}\text { Total } \\
(\mathrm{n}=179,265)\end{array}$ & $\begin{array}{c}\text { Non-ARB/ACEI } \\
(\mathrm{n}=143,583)\end{array}$ & $\begin{array}{c}\text { ARB } \\
(n=33,626)\end{array}$ & $\begin{array}{c}\text { ACEI } \\
(\mathrm{n}=2,056)\end{array}$ & $p$ value \\
\hline Age, yr & $38.93 \pm 36.33$ & $29.46 \pm 34.10$ & $77.15 \pm 11.27$ & $74.90 \pm 19.14$ & $<0.0001$ \\
\hline $0-19$ & $87,763(48.96)$ & $87,651(61.05)$ & $12(0.04)$ & $100(4.86)$ & $<0.0001$ \\
\hline $20-59$ & $16,913(9 \cdot 43)$ & $14,245(9.92)$ & $2,572(7.66)$ & $96(4.66)$ & \\
\hline $60-79$ & $36,507(20.36)$ & $21,112(14.71)$ & $14,581(43 \cdot 36)$ & $814(39 \cdot 59)$ & \\
\hline$\geq 80$ & $38,082(21.24)$ & $20,575(14 \cdot 33)$ & $16,461(48.95)$ & $1,046(50.88)$ & \\
\hline Female sex & $88,560(49.40)$ & $70831(49 \cdot 33)$ & $16938(50.37)$ & $791(38.87)$ & $<0.0001$ \\
\hline \multicolumn{6}{|l|}{ Comorbidity } \\
\hline Any 1 comorbidity & $88,509(47 \cdot 70)$ & $50,167(34.94)$ & $33,323(99.10)$ & $2,019(98.20)$ & $<0.0001$ \\
\hline Hypertension & $59,729(33 \cdot 32)$ & $25,007(17.42)$ & $32,809(95 \cdot 57)$ & $1,913(93.04)$ & $<0.0001$ \\
\hline Diabetes mellitus & $41,868(23 \cdot 36)$ & $20,511(14.29)$ & $20,161(59.96)$ & $1,196(58.17)$ & $<0.0001$ \\
\hline Coronary artery disease & $22,761(12.70)$ & $10,021(6.98)$ & $11,656(34.66)$ & $1,084(52.72)$ & $<0.0001$ \\
\hline Heart failure & $17,568(9.80)$ & $7,679(5 \cdot 35)$ & $8,868(26.37)$ & $1,021(49.66)$ & $<0.0001$ \\
\hline Stroke & $19,800(11.05)$ & $9,664(6.73)$ & $9,554(28.41)$ & $582(28.31)$ & $<0.0001$ \\
\hline COPD & $45,053(25.13)$ & $28,983(20.19)$ & $15,094(44.89)$ & $976(47 \cdot 47)$ & $<0.0001$ \\
\hline Cancer (any) & $12,390(6.91)$ & $7,265(5.06)$ & $4,792(14.25)$ & $333(16.20)$ & $<0.0001$ \\
\hline Chronic kidney disease & $6,389(3.56)$ & $2,063(1.44)$ & $4,042(12.02)$ & $284(13.81)$ & $<0.0001$ \\
\hline \multicolumn{6}{|l|}{ Medications } \\
\hline ARBs & $33,626(18.76)$ & - & $33,626(100)$ & - & \\
\hline ACEIs & $2,056(1.15)$ & - & - & $2,056(100)$ & \\
\hline Death within 60 days & $13,284(7 \cdot 41)$ & $7,612(5 \cdot 30)$ & $5,243(15 \cdot 59)$ & $2,056(20.87)$ & $<0.0001$ \\
\hline
\end{tabular}

Values are presented as mean \pm standard deviation or number (\%).

ARB, angiotensin receptor blocker; ACEI, angiotensin-converting enzyme inhibitor; COPD, chronic obstructive pulmonary disorder. 
Supplementary Table 2. Results of univariable regression analysis for the mortality within 60 days

\begin{tabular}{|c|c|c|c|c|c|}
\hline Variable & No. patients & No. death & HR & $95 \% \mathrm{CI}$ & $p$ value \\
\hline \multicolumn{6}{|l|}{ Age, yr } \\
\hline $0-64$ & 111,602 & 634 & 1 & & \\
\hline$\geq 65$ & 67,663 & 12,650 & 36.223 & $33.446-39.230$ & $<0.0001$ \\
\hline \multicolumn{6}{|l|}{ Sex } \\
\hline Male & 90,705 & 7,429 & 1 & & \\
\hline Female & 88,560 & 5,855 & 0.803 & $0.776-0.831$ & $<0.0001$ \\
\hline \multicolumn{6}{|c|}{ Comorbidity (upper, no; lower, yes) } \\
\hline \multirow[t]{2}{*}{ Hypertension } & 119,536 & 2,884 & 1 & & \\
\hline & 59,729 & 10,400 & 7.814 & $7 \cdot 498-8.143$ & $<0.0001$ \\
\hline \multirow[t]{2}{*}{ Diabetes mellitus } & 137,397 & 6,344 & 1 & & \\
\hline & 41,868 & 6,940 & 3.822 & $3.694-3.955$ & $<0.0001$ \\
\hline \multirow[t]{2}{*}{ Coronary artery disease } & 156,504 & 9,310 & 1 & & \\
\hline & 22,761 & 3,974 & 3.120 & $3.006-3.238$ & $<0.0001$ \\
\hline \multirow[t]{2}{*}{ Stroke } & 159,465 & 8,983 & 1 & & \\
\hline & 19,800 & 4,301 & 4.199 & $4.049-4.354$ & $<0.0001$ \\
\hline \multirow[t]{2}{*}{ COPD } & 134,212 & 7,522 & 1 & & \\
\hline & 45,053 & 5,762 & 2.366 & $2.286-2.449$ & $<0.0001$ \\
\hline \multirow[t]{2}{*}{ Cancer (any) } & 166,875 & 10,448 & 1 & & \\
\hline & 12,390 & 2,836 & 4.000 & $3.837-4.169$ & $<0.0001$ \\
\hline \multirow[t]{2}{*}{ Chronic kidney disease } & 172,876 & 11,850 & 1 & & \\
\hline & 6,389 & 1,434 & $3 \cdot 553$ & $3.364-3.753$ & $<0.0001$ \\
\hline \multirow[t]{2}{*}{ Heart failure } & 161,697 & 9,656 & 1 & & \\
\hline & 17,568 & 3,628 & 3.737 & $3.597-3.882$ & $<0.0001$ \\
\hline \multicolumn{6}{|l|}{ Medication } \\
\hline Non-ACEIs/ARBs & 143,583 & 7,612 & 1 & & \\
\hline ARBs & 33,626 & 5,243 & 3.100 & $2.992-3.211$ & $<0.0001$ \\
\hline ACEIs & 2,056 & 429 & 4.266 & $3.871-4.702$ & $<0.0001$ \\
\hline Non-ACEIs/ARBs & 143,583 & 7,612 & 1 & & \\
\hline ARBs or ACEIs & 35,682 & 5,672 & 3.165 & $3.058-3.276$ & $<0.0001$ \\
\hline
\end{tabular}

HR, hazard ratio; CI, confidence interval; COPD, chronic obstructive pulmonary disorder. ACEI, angiotensin-converting enzyme inhibitor; ARB, angiotensin receptor blocker. 
Supplementary Table 3. Results of multivariable regression analysis of ARBs and ACEIs for the mortality within 60 days

\begin{tabular}{|c|c|c|c|c|c|}
\hline Variable & No. patients & No. death & HR & $95 \% \mathrm{CI}$ & $p$ value \\
\hline \multicolumn{6}{|l|}{ Age, yr } \\
\hline $0-64$ & 111,602 & 634 & 1 & & \\
\hline$\geq 65$ & 67,663 & 12,650 & 27.036 & $24.765-29.516$ & $<0.0001$ \\
\hline \multicolumn{6}{|l|}{ Sex } \\
\hline Male & 90,705 & 7,429 & 1 & & \\
\hline Female & 88,560 & 5,855 & 0.862 & $0.832-0.893$ & $<0.0001$ \\
\hline \multicolumn{6}{|c|}{ Comorbidity (upper, no; lower, yes) } \\
\hline \multirow[t]{2}{*}{ Hypertension } & 119,536 & 2,884 & 1 & & \\
\hline & 59,729 & 10,400 & 1.433 & $1.363-1.507$ & $<0.0001$ \\
\hline \multirow[t]{2}{*}{ Diabetes mellitus } & 137,397 & 6,344 & 1 & & \\
\hline & 41,868 & 6,940 & 1.061 & $1.022-1.100$ & 0.0017 \\
\hline \multirow[t]{2}{*}{ Coronary artery disease } & 156,504 & 9,310 & 1 & & \\
\hline & 22,761 & 3,974 & 0.982 & $0.943-1.024$ & 0.3988 \\
\hline \multirow[t]{2}{*}{ Stroke } & 159,465 & 8,983 & 1 & & \\
\hline & 19,800 & 4,301 & 1.356 & $1.306-1.408$ & $<0.0001$ \\
\hline \multirow[t]{2}{*}{ COPD } & 134,212 & 7,522 & 1 & & \\
\hline & 45,053 & 5,762 & 0.864 & $0.833-0.895$ & $<0.0001$ \\
\hline \multirow[t]{2}{*}{ Cancer (any) } & 166,875 & 10,448 & 1 & & \\
\hline & 12,390 & 2,836 & $1.631-$ & $1.563-1.702$ & $<0.0001$ \\
\hline \multirow[t]{2}{*}{ Chronic kidney disease } & 172,876 & 11,850 & 1 & & \\
\hline & 6,389 & 1,434 & 1.264 & $1.193-1.338$ & $<0.0001$ \\
\hline \multirow[t]{2}{*}{ Heart failure } & 161,697 & 9,656 & 1 & & \\
\hline & 17,568 & 3,628 & 1.281 & $1.228-1.335$ & $<0.0001$ \\
\hline \multicolumn{6}{|l|}{ Medication } \\
\hline Non-ACEIs/ARBs & 143,583 & 7,612 & 1 & & \\
\hline ARBs & 33,626 & 5,243 & 0.853 & $0.820-0.887$ & $<0.0001$ \\
\hline ACEIs & 2,056 & 429 & 1.089 & $0.986-1.203$ & 0.0987 \\
\hline Non-ACEIs/ARBs & 143,583 & 7,612 & 1 & & \\
\hline ARBs or ACEIs & 35,682 & 5,672 & 0.866 & $0.834-0.900$ & $<0.0001$ \\
\hline
\end{tabular}

Adjusted for age, sex, the history of medication (statins in case of ARBs/ACEIs), the history of comorbidities (hypertension, diabetes mellitus, cancer, COPD, stroke, coronary artery disease, heart failure, and chronic kidney disease, statin use) before the diagnosis of coronavirus disease 2019 .

ARB, angiotensin receptor blocker; ACEI, angiotensin-converting enzyme inhibitor; HR, hazard ratio; CI, confidence interval; COPD, chronic obstructive pulmonary disorder. 


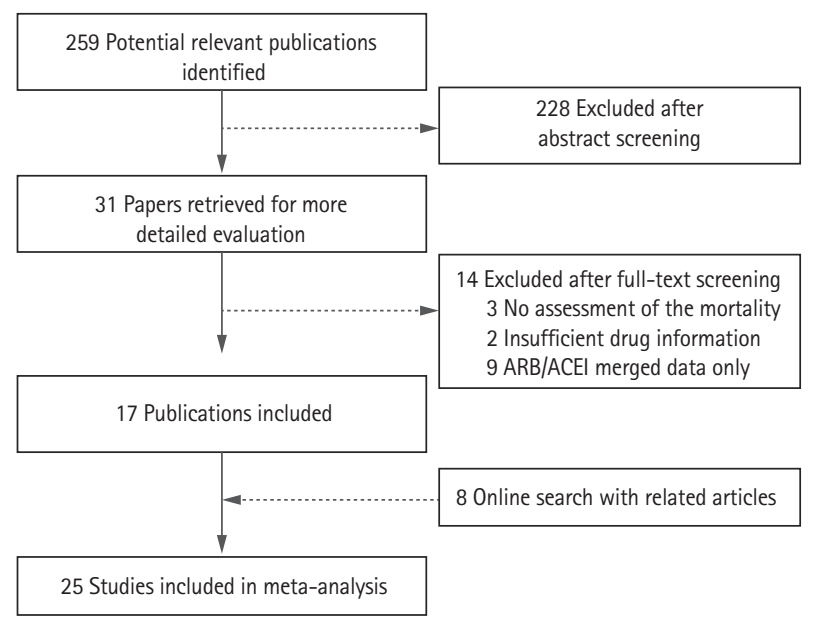

Supplementary Figure 1. Flow diagram for meta-analysis. ARB, angiotensin receptor blocker; ACEI, angiotensin-converting enzyme inhibitor. 


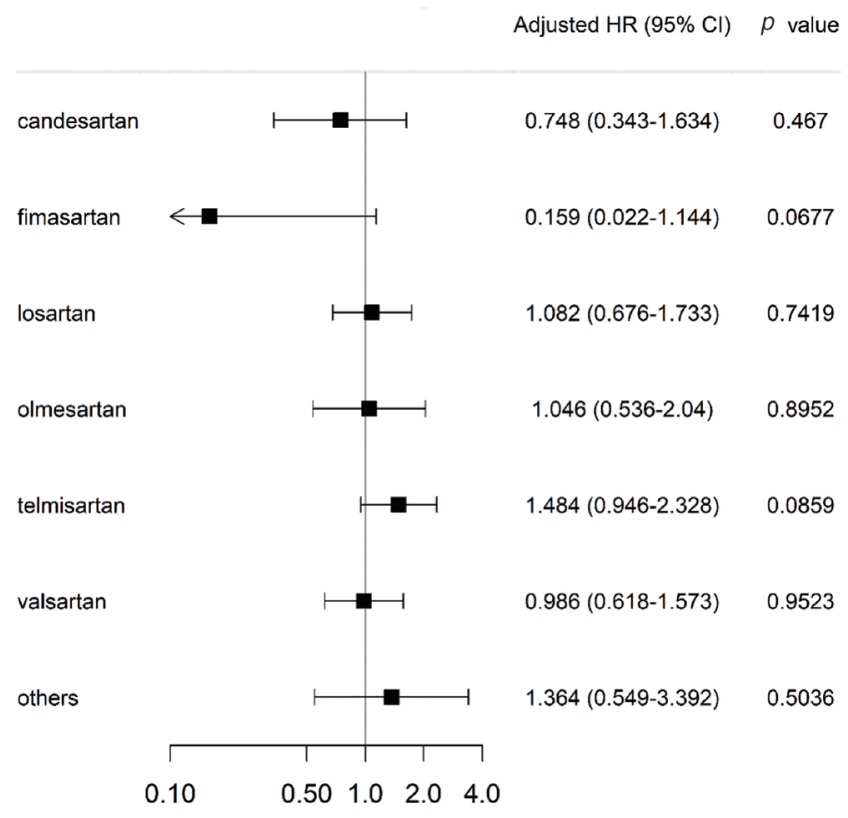

Supplementary Figure 2. Subgroup analysis for survival within 60 days by each angiotensin receptor blocker. Only individual drugs having sufficient prescription numbers for analysis were analyzed. HR, hazard ratio; CI, confidence interval. 